\begin{tabular}{l} 
SCIENCE \& TECHNOLOGY \\
Journal homepage: http://www.pertanika.upm.edu.my/ \\
\hline PERTANIKA
\end{tabular}

\title{
Effect of Water Absorption on Flexural Properties of Kenaf/Glass Fibres Reinforced Unsaturated Polyester Hybrid Composites Rod
}

\author{
Bassam Hamid Alaseel', Mohamed Ansari Mohamed Nainar ${ }^{1,2 *}$, Noor Afeefah \\ Nordin1, Zainudin Yahya ${ }^{1}$ and Mohd Nazim Abdul Rahim ${ }^{1}$ \\ ${ }^{1}$ Mechanical Engineering Department, Universiti Tenaga Nasional, Jalan IKRAM-UNITEN, 43000, Kajang, \\ 43000, Selangor, Malaysia \\ ${ }^{2}$ Institute of Power Engineering, Universiti Tenaga Nasional, Jalan IKRAM-UNITEN, 43000, Kajang, 43000, \\ Selangor, Malaysia
}

\begin{abstract}
This study investigates the effect of water absorption on the flexural strength of kenaf/ glass/unsaturated polyester (UPE) hybrid composite solid round rods used for insulating material applications. Three volume fractions of kenaf/glass fibre 20:80 (KGPE20), 30:70 (KGPE30), and 40:60 (KGPE40) with three different fibre arrangement profiles of kenaf fibres were fabricated by using the pultrusion technique and were aimed at studying the effect of kenaf fibres arrangement profile and its content in hybrid composites. The fibre/ resin volume fraction was maintained constant at 60:40. The dispersion morphologies of tested specimens were observed using the scanning electron microscope (SEM). The findings were compared with pure glass fibre-reinforced UPE (control) composite. The water absorption results showed a clear indication of how it influenced the flexural strength of the hybrid and non-hybrid composites. The least affected sample was observed in the 30KGPE composite type, wherein the kenaf fibre was concentrated at the centre of a cross-section of the composite rod.

ARTICLE INFO

Article history:

Received: 23 May 2021

Accepted: 11 August 2021

Published: 10 January 2022

DOI: https://doi.org/10.47836/pjst.30.1.22

$\overline{\text { E-mail addresses: }}$

bsmaq.it@gmail.com (Alaseel Bassam)

ansari@uniten.edu.my (Mohamed Ansari Mohamed Nainar)

afeefahnordin1@gmail.com (Noor Afeefah Nordin)

zai@uniten.edu.my (Zainudin Yahya)

nazim2106@gmail.com (Mohd Nazim Abdul Rahim)

* Corresponding author

The water absorption reduced the flexural strength by $7 \%, 40 \%, 24 \%$, and $38 \%$ of glass/UPE (control), 20KGPE, 30KGPE, and $40 \mathrm{KGPE}$ composites, respectively. In randomly distributed composite types, the water absorption is directly proportional to the volume fraction of kenaf fibre. At the same time, flexural properties were inversely proportional to the volume fraction
\end{abstract}


of kenaf fibres. Although the influence of water absorption on flexural strength is low, the flexural strength of pultruded hybrid composites was more influenced by the arrangement of kenaf fibre in each composite type than its fibre loading.

Keywords: Flexural properties, glass fibres, hybrid composite, insulating material, kenaf fibres, water absorption

\section{INTRODUCTION}

The recent advancement in natural fibre-reinforced composites has sparked researchers' interest in utilising these composites to lower the dependency on petroleum-based materials. Manufacturers and scientists are concerned about natural fibre reinforced composites because it is lightweight, relatively more substantial, non-toxic and considered to be excellent products that can be utilised in construction, automotive as well as in furniture industry (Saba et al., 2015). Reducing waste and chemical emissions (produced through using non-degradable materials) by relying on eco-friendly materials, reducing costs, decreasing the insulators' weight, and shortening maintenance time have become areas of attention for environmentalists, manufacturers, and researchers. Furthermore, natural fibre composites are more flexible, stiffer and can withstand high impact stress compared to conventional materials (Sarikaya et al., 2019). Besides, natural fibres are also abundantly available, renewable, possess low density as well as to have thermic insulation properties (Liu et al., 2019).

The origin of natural fibres is classified either as animal or plant-based. Some of the commonly found animal-based fibres are wool and silk, while natural fibres based on plants can be obtained from kenaf, sisal, coir, ramie, jute, bamboo, pineapple and various plant resources (Nunna et al., 2012). These fibres have numerous advantages, including relatively high modulus, lightweight, safe, easy manufacture, and their natural ability to absorb carbon dioxide during their growth process. The dimensional and mechanical characteristics of these fibres determine how well they can be used. These characteristics include the origin, harvest and environment conditions, plant age, and extraction methods (Kabir et al., 2012).

Kenaf plant is well known as a green and sustainable material whereby it is economically cheap and commercially available (Saba et al., 2015). The development of a sustainable product from kenaf fibres is becoming more prevalent for use in the automotive, sports (Seman et al., 2019), food packaging (Hamouda et al., 2019), construction, furniture (Dahy, 2019), textiles, and paper pulp (Sarikaya et al., 2019) sectors. Since kenaf fibre has started to be used in electrical applications, it is crucial for researchers to elucidate its electrical behaviour to identify its merits and demerits (Fares et al., 2019).

The insulator in electricity-transferring power lines is one of the critical components of high voltage networks because it plays a primary role in maintaining the continuity of 
the power transmitting system. Insulators could be manufactured from ceramic (glass and porcelain) or non-ceramic (polymer composites). Polymer insulators developed quickly over the past 60 years as an alternative for glass fibres insulators commonly used in the industry. Polymer insulators are also called Fibre-Reinforced Polymer (FPR) insulators and composite insulators. This type of insulator consists of three components: (i) Silicon rubber housing, (ii) FRP rod and (iii) steel end-fitting. It is the most significant part of the power transmission system, whereby a failure in the insulator element can cause system failure, leading to cutting off in power supply (Ghosh et al., 2015). The insulator rod's main aim is to supply mechanical support to a high voltage transferring line by transmitting the conductor load to a tower, thereby providing insulation between the conductor and tower. This insulator rod has traditionally been manufactured from tempered glass or porcelain (Bansal, 1996). Over the past few years, glass-reinforced polymer (GRP) insulator rods have quickly replaced the conventional porcelain in high voltage (HV) power transmission lines (Bansal et al., 1995). Multiple weather sheds and a specific rubber alloy are used to protect the insulator rod. This protection technique is used to protect the insulator rod from moisture and pollution completely. In particular cases, the FRP insulator may be unprotected and allow water to get to the insulator surface. It can happen when the rubber alloy thickness is insufficient, damaged by abrasion, or due to cracks (Kumosa et al., 2004). In some instances, abrasion and cracks occur in the suspension insulator due to bird shooters or during the impact of fragments from a car bomb explosion in war zone regions.

Hybridisation is a combination of different kinds of fibres into one matrix. This combination between kenaf (natural fibre) and glass (synthetic fibre) provides better composites that possess the merits of both components. This method can offer a higher strength-to-weight ratio, longer fatigue life, and better mechanical properties than singlefibre composites. In addition, the alteration of glass fibre by natural fibre will considerably decrease the quantity and proportion of the glass fibre used in production, thus reducing its waste. The crossbreeding of kenaf fibres with glass fibres is widely recognised as a major choice for industrialists and researchers seeking to reduce environmental risks (Hamidon et al., 2018).

Bassam et al. (2019) studied the water absorption of kenaf/glass/UPE pultruded hybrid composites. Three different volume proportions of kenaf fibres with different fibre arrangements were applied to investigate the water absorption of the hybrid composites. Kenaf-glass fibres hybridisation showed that the water absorption of hybrid composites increased up to $10 \%$, as shown in Figure 1 . The water absorption was also influenced by kenaf fibres arrangement profiles.

Since numerous studies have found that mechanical properties were influenced by water absorption, this current research describes the leverage of water assimilation on flexural strength of kenaf/glass fibres hybrid composite used in insulator applications as a function 


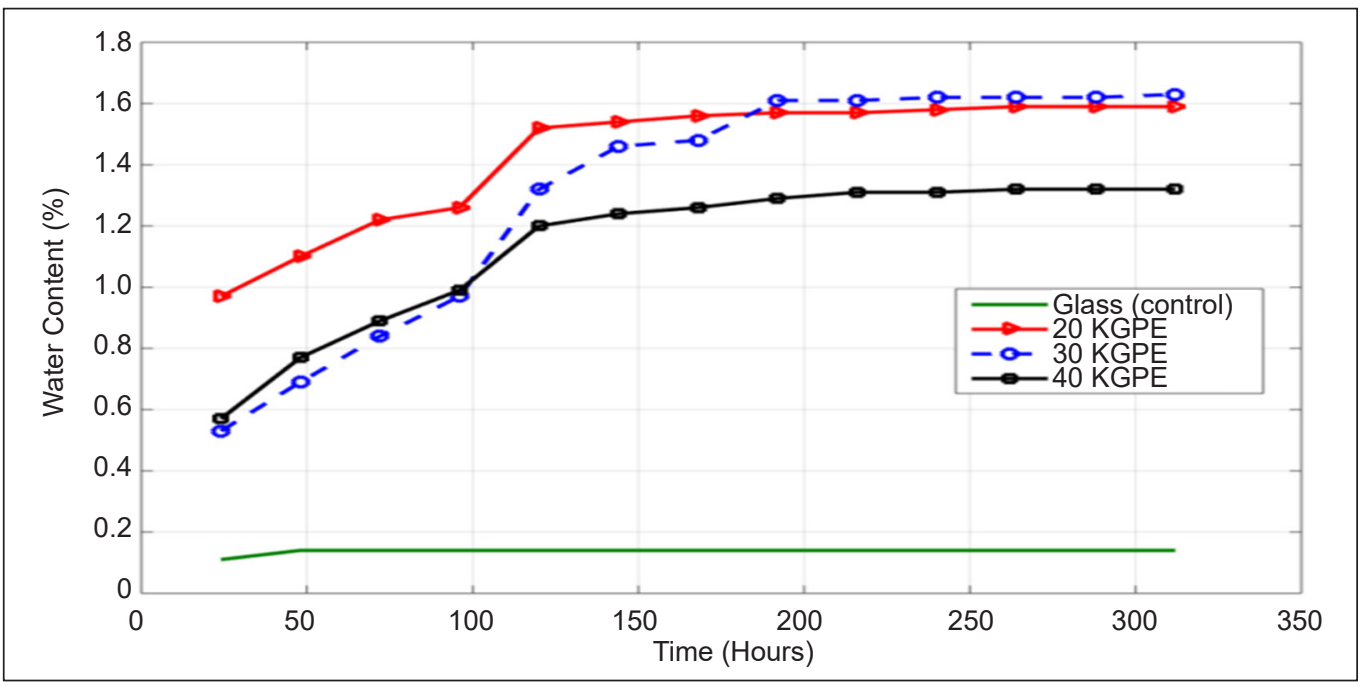

Figure 1. Water absorption of kenaf/glass composites

of genealogical volume proportion of two different fibres (César dos Santos et al., 2020; Hamdan et al., 2019; Khan et al., 2019; Li et al., 2016; Ma et al., 2018; Nayak et al., 2016; Quino et al., 2020; Rajeshkumar, 2020; Swain et al., 2020; Zhang et al., 2020). In addition to this, three-volume fractions of kenaf fibres with three various arrangement profiles had been fabricated, and their flexural properties have been evaluated. The influence of kenaf fibre hybridisation on the water assimilation tendency of hybrid composites was studied.

\section{METHODS AND MATERIALS}

\section{Materials}

Glass fibres (4400 texes) and kenaf yarns (1000 tex) were supplied from the local supplier in Malaysia. UPE resin, hardener, and fillers were purchased from Innovation Pultrusion Sdn. Bhd., Seremban, Malaysia. Kenaf fibres used in this study are made from kenaf bast. It is an economically cheap fibre compared with other natural fibres. Table 1 describes the physical and mechanical properties of glass fibres (GF) and kenaf fibres (KF).

Unsaturated-Polyester (UPE) resin is a common thermoset polymer widely used in engineering industries. UPE is employed to manufacture pultruded composite, utilising

\section{Table 1}

Physical and mechanical properties of glass fibres (GF) and kenaffibres (KF) (Mahjoub et al., 2014, Sanjay et al., 2018, Saba et al., 2016)

\begin{tabular}{lccccc}
\hline Fibres & $\begin{array}{c}\text { Density } \\
\mathrm{g} / \mathrm{cm}^{3}\end{array}$ & $\begin{array}{c}\text { Diameter } \\
\mu \mathrm{m}\end{array}$ & $\begin{array}{c}\text { tensile strength } \\
\mathrm{MPa}\end{array}$ & $\begin{array}{c}\text { Young's modulus } \\
\text { GPa }\end{array}$ & $\begin{array}{c}\text { elongation to } \\
\text { break } \%\end{array}$ \\
\hline GF & 2.62 & $<17$ & 3400 & 73 & 3.4 \\
$\mathrm{KF}$ & $1.19-1.4$ & $10-17.7$ & $295-600$ & $40-53$ & $1.5-3.5$ \\
\hline
\end{tabular}


a pultrusion approach. UPE is being utilised in a wide range of kenaf and glass fibre composite implementations. UPE resin has an excellent chemical resistance property, where its properties are: (3\% elongation to break, 3GPa Young's modulus, 50-65 MPa tensile strength, and $1.2 \mathrm{~g} / \mathrm{cm}^{3}$ density) (Ouarhim et al., 2019; Soares \& Preto, 2016).

\section{Preparation Process}

The volume fraction of fibres (both kenaf and glass fibres together) to UPE resin was $65 \%$. Kenaf/glass fibre reinforced UPE hybrid composites were fabricated using a pultrusion machine (Pultrex Px-1000-6T) at Innovative Pultrusion Sdn. Bhd industry, Seremban, Malaysia. Table 2 demonstrates

Table 2

Kenaf/glass/UPE hybrid composite types

\begin{tabular}{ccc}
\hline Composite type & $\begin{array}{c}\text { Kenaf fibres } \\
\text { (vol.\%) }\end{array}$ & $\begin{array}{c}\text { Glass fibres } \\
\text { (vol.\%) }\end{array}$ \\
\hline 20KGPE & $20 \%$ & $80 \%$ \\
$30 \mathrm{KGPE}$ & $30 \%$ & $70 \%$ \\
$40 \mathrm{KGPE}$ & $40 \%$ & $60 \%$ \\
\hline
\end{tabular}
the hybrid composite types.

Three Kenaf/glass hybrid composites with different volume fractions were fabricated with a circular cross-section of $24.7 \mathrm{~mm}$ diameter. The volume fraction of fibres is the main factor for adjusting the flexural properties of hybrid composites (Aslan et al., 2013). Therefore, Equation 1 was used to calculate the number of kenaf and glass fibres according to the constant local fibre volume fraction criterion (Hashemi et al., 2018).

$$
\left.\left(\frac{n_{r k}}{n_{r k}^{o}}\right)+\frac{n_{r G}}{n_{r G}^{o}}\right)=1
$$

Where,

$\mathrm{n} \_\mathrm{rK}^{\wedge} \mathrm{o}$ is the number of kenaf yarns in kenaf/UPE non-hybrid composite,

$\mathrm{n} \_\mathrm{rG}^{\wedge} \mathrm{o}$ is glass roving in glass/UPE non-hybrid composite,

$\mathrm{n} \_\mathrm{rK}^{\wedge}$ is the number of kenaf yarns in kenaf/UPE non-hybrid composite, and

$\mathrm{n}_{\mathrm{r}} \mathrm{rG}^{\wedge}$ is the number of glasses roving in a hybrid composite.

The gravimetrical measurement of weight fraction of fibre and density of composite, matrix, and fibres were used to calculate the volume fraction (Hashemi et al., 2016).

Figures 2(a), 2(b), and 2(c) demonstrates the cross-section of three types of hybrid composites (20KGPE, 30KGPE, 40KGPE) respectively. In 20KGPE composite (a), the volume of kenaf fibres was $20 \%$, and the kenaf/glass fibres were arranged as half of the cross-section. In 30KGPE composite (b), 30vol.\% of kenaf fibres were concentrated in the core of the solid rod. In both 20KGPE and 30KGPE composite types, the kenaf fibres were concentrated in the core and surrounded by glass fibres. In the 40KGPE composite type, 40vol.\% of fibres was kenaf fibres arranged throughout the whole diameter of the cross-section. Nonetheless, it was shown that the distribution of the kenaf fibre is not consistent because of the nature of the plant fibre, which is twisted, non-uniformity and the discontinuity of its structure (Hashemi et al., 2016). 


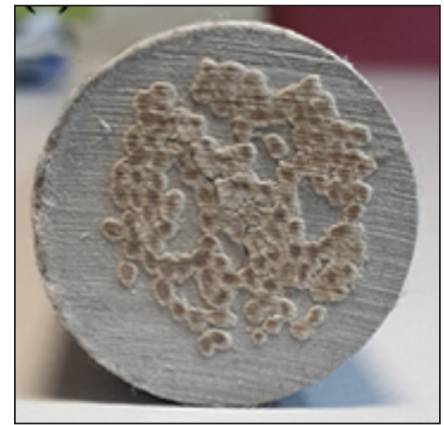

(a)

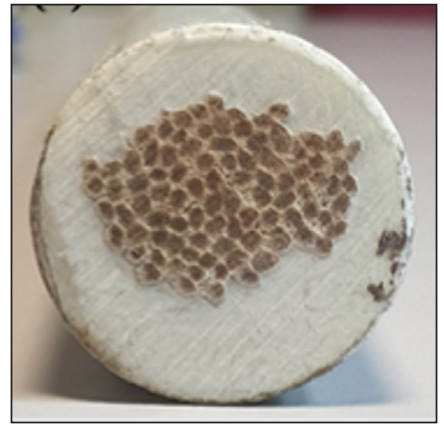

(b)



(c)

Figure 2. (a) 20KGPE, (b) $30 \mathrm{KGPE}$, and (c) 40KGPE composite types

\section{Water Absorption Test}

A water absorption test was conducted to define the influence of moisture on the composite characteristics (Sanjay et al., 2018) and loss of composite strength (Azwa \& Yousif, 2013). Water absorption testing was performed by taking cylindrical bars of length $200 \mathrm{~mm}$ and diameter $24.7 \mathrm{~mm}$. The test was done in three replicates for each specimen, specifically following the procedures described in ASTM standard D5229/D5229M-92 (ASTM standard, 2010). All specimens were cleaned to remove contaminants from machining, including the dirt and oil prior to submersion in water. The initial weight of the specimen was measured before they were immersed in distilled water. The weight shift was calculated at regular intervals (every 24 hours) using an analytical balance with $0.1 \mathrm{mg}$ accuracy. The test was continued until the specimens reached an equilibrium state. Then, the water absorption content was calculated using Equation 2:

$$
\% \Delta m_{w}=\frac{m_{w}-m_{d}}{m_{d}} \times 100 \%
$$

Where, $m_{w}$ is the weight of the specimen at the time of collecting data (wet), and $m_{d}$ is the weight of the dry specimen. Fick's law has been used to calculate the absorption rate of composites as shown in Equation 3:

$$
\frac{M_{t}}{M_{e}}=2\left(\frac{D}{\pi L^{2}}\right)^{\frac{1}{2}}
$$

Where, $\mathrm{M}_{\mathrm{t}}(\mathrm{g})$ is the mass gain at time $\mathrm{t}(\mathrm{s}), \mathrm{M}_{\mathrm{e}}(\mathrm{g})$ is the mass gain at equilibrium, $2 L$ is the thickness of the specimen $(\mathrm{cm})$ and $D$ is the diffusion coefficient $\left(\mathrm{cm}^{2} \mathrm{~s}^{-1}\right)(\mathrm{Li}$ et al., 2018).

\section{Flexural Strength Test}

The flexural strength of any material is usually based on the maximum bending that it can tolerate until it breaks (Mishra et al., 2017). The present test was carried out according to the 
three-point loading method (ASTM D790-10) by using Zwick/Roell machine following the three-point bending method (Vickers et al., 2014; Sapiai et al., 2015). Every specimen used measures $200 \mathrm{~mm}$ in length with a diameter of $24.7 \mathrm{~mm}$. It is held with a steady head speed of $10 \mathrm{~mm} / \mathrm{min}$ during the whole test. The maximum stress of fibre depends on specimen dimension and the load applied. Equation 4 is used to calculate the maximum stress.

$$
S=\frac{3 F L}{\pi d^{3}}
$$

where, $\mathrm{S}=$ stress $(\mathrm{MPa}), \mathrm{F}=$ load $(\mathrm{kN}), \mathrm{L}=$ length $(\mathrm{mm})$, and $\mathrm{d}=\operatorname{diameter}(\mathrm{mm})$. The mean value of the three results obtained is used to calculate the flexural strength. The flexural tests were carried out on the specimens after water absorption, and the mean value of the specimens of each composite type was recorded.

\section{Scanning Electron Microscopy (SEM)}

Morphological properties of the samples were characterised using SEM to obtain images with high resolution and magnification. The study used SEM to analyse material damage post flexural test by observing the fibre and matrix properties. This method is mandatory since it plays a vital role in understanding the material's physical and mechanical properties. The hybrid composites were properly cleaned and mounted on the stubs, using a silver paste for examination purposes. Morphological properties of each specimen were characterised using a JEOL, JSM-6010PUL/LV scanning electron microscope at Universiti Tenaga Nasional, Kajang, Selangor, Malaysia, with SEM magnification of $300 \times, 100 \times$, and $30 \times$.

\section{RESULTS AND DISCUSSION}

\section{Water Absorption}

Based on the literature review, the insulator rod that has been in service is possible to be exposed to moisture and rain. The existence of acids on the insulator rod surface was because of acid rain or moist air. Based on the type of polymeric insulator rod, the presence of enough water may lead to failure(Ansari et al., 2021). Therefore, the water absorption test was conducted to calculate the weight of water absorbed by specimens - the test of 20vol.\%, 30vol.\%, and 40vol.\% of kenaf/glass/UPE hybrid composite rod was carried out under room temperature. The findings of hybrid composite rods were compared with pure glass fibre composite rods (control samples). Three samples of each composite type were tested, and the average reading was reported. The hybrid composites rapidly absorbed the water after immersion. After that, water absorption increased significantly during the next three days (days 2-4). All specimens of hybrid composites reached saturation state after 8-10 days, while the non-hybrid composite specimens (control) reached this state after two days. The water absorption of non-hybrid composite (control) was $0.15 \%$; meanwhile, 
the water absorption of 20KGPE, 30KGPE, and 40KGPE (pultruded hybrid composites) was $1.59 \%, 1.63 \%$, and $1.32 \%$, respectively.

Ordinarily, replacing synthetic fibre with natural fibre in hybrid composites increases water absorption, which was observed in past research (Bassam et al., 2019; Saba et al., 2016). Previous studies have proven the type of fibres and their surface, resin viscosity, volume fraction (fibres-fibres and fibres-resin), and temperature-controlled water spreading operation in hybrid composites (Ellyin \& Maser, 2004). In addition, the water uptake process is also affected by the orientation and arrangement of the fibres, whereby the kenaf fibres concentrated in the centre of the rod 30KGPE had maximum water absorption. The hybridisation of two or more different fibres utilised in the hybrid composite caused inferior attachment between fibres and resin. This incomplete attachment disabled the fibres to be saturated with resin, and thus, fibres are not in equilibrium for moisture absorption.

The voids inside the material were the main water-storage pathway for the composites. Due to the test occurring at room temperature and using tap water, no cracking mechanism was acting on the FRP. Consequently, the water storage capacity inside composites material remained unchanged. Therefore, constant saturation water uptake may be appropriate for the current four immersion cases. Table 3 illustrates the diffusion coefficient $(D)$ for composites.

It was observed that the diffusion coefficient (D) of pure glass fibre composite (control) is almost constant for all the testing periods. At the same time, it gradually increased for all the three compositions of kenaf/glass hybrid composites. Additional care was taken during the mixing of raw materials (fibres, resin, and additives) when passing through the die heater in the pultrusion machine during the fabrication process, leading to minimal voids

Table 3

Diffusion coefficient (D) for kenaf/glass/UPE hybrid composites

\begin{tabular}{ccccc}
\hline \multirow{2}{*}{ Day } & \multicolumn{4}{c}{ Diffusion coefficient $(\mathrm{D})\left({\left.\mathrm{x} 10^{-13} \mathrm{~m}^{2} / \mathrm{s}\right)}\right.$} \\
\cline { 2 - 5 } & Glass (control) & 20KGPE & 30KGPE & 40KGPE \\
\hline 1 & 0.784 & 0.761 & 0.761 & 0.770 \\
2 & 0.785 & 0.776 & 0.769 & 0.777 \\
3 & 0.786 & 0.778 & 0.771 & 0.779 \\
4 & 0.786 & 0.780 & 0.774 & 0.781 \\
5 & 0.786 & 0.781 & 0.775 & 0.784 \\
6 & 0.786 & 0.785 & 0.781 & 0.784 \\
7 & 0.786 & 0.785 & 0.783 & 0.784 \\
8 & 0.786 & 0.785 & 0.783 & 0.785 \\
9 & 0.786 & 0.786 & 0.785 & 0.785 \\
10 & 0.786 & 0.786 & 0.785 & 0.785 \\
11 & 0.786 & 0.786 & 0.786 & 0.786 \\
12 & 0.786 & 0.786 & 0.786 & 0.786 \\
13 & 0.786 & 0.786 & 0.786 & 0.786 \\
\hline
\end{tabular}


and internal moisture. As a result, it slightly improved the diffusion coefficient, and there is no notable difference in the value ' $\mathrm{D}$ ' irrespective of the filler volume \% (loading level).

\section{Flexural Properties}

The effect of water absorption on the flexural strength of kenaf/glass/ UPE hybrid composite is shown in Figure 3. The average of three samples of each composite type was recorded and analysed in this section. The flexural strength of 20KGPE, 30KGPE, and 40KGPE before water absorption was $148 \mathrm{MPa}, 112 \mathrm{MPa}$, and $190 \mathrm{MPa}$, while the flexural strength after water absorption was $89.2 \mathrm{MPa}, 109 \mathrm{MPa}$, and $118 \mathrm{MPa}$, respectively. The standard deviation of error bars with \pm 5 was given out for the average value of every three batches. This deviation of errors was due to the difference of diameters of tex that constitute kenaf fibre and the degree of intertwining between these texes. The fibre with tighter intertwining needs more energy consumption due to mechanical friction, resulting in the difference in flexural strength results.

Unequivocally, water absorption can impair the chemical bonds of composites, causing voids, and dissolve the chemical bonds between the fibres and resins. Voids might produce inner and surface microcracks, resulting in decreased mechanical properties of composites. The findings of the current study revealed that the influence of water absorption on flexural properties of composites with fewer chemical bonds between two different types of fibres (30KGPE) was smaller than the composites that have more chemical bonds between two different types of fibres (20KGPE and 40KGPE). Thus, the composites with fewer contact

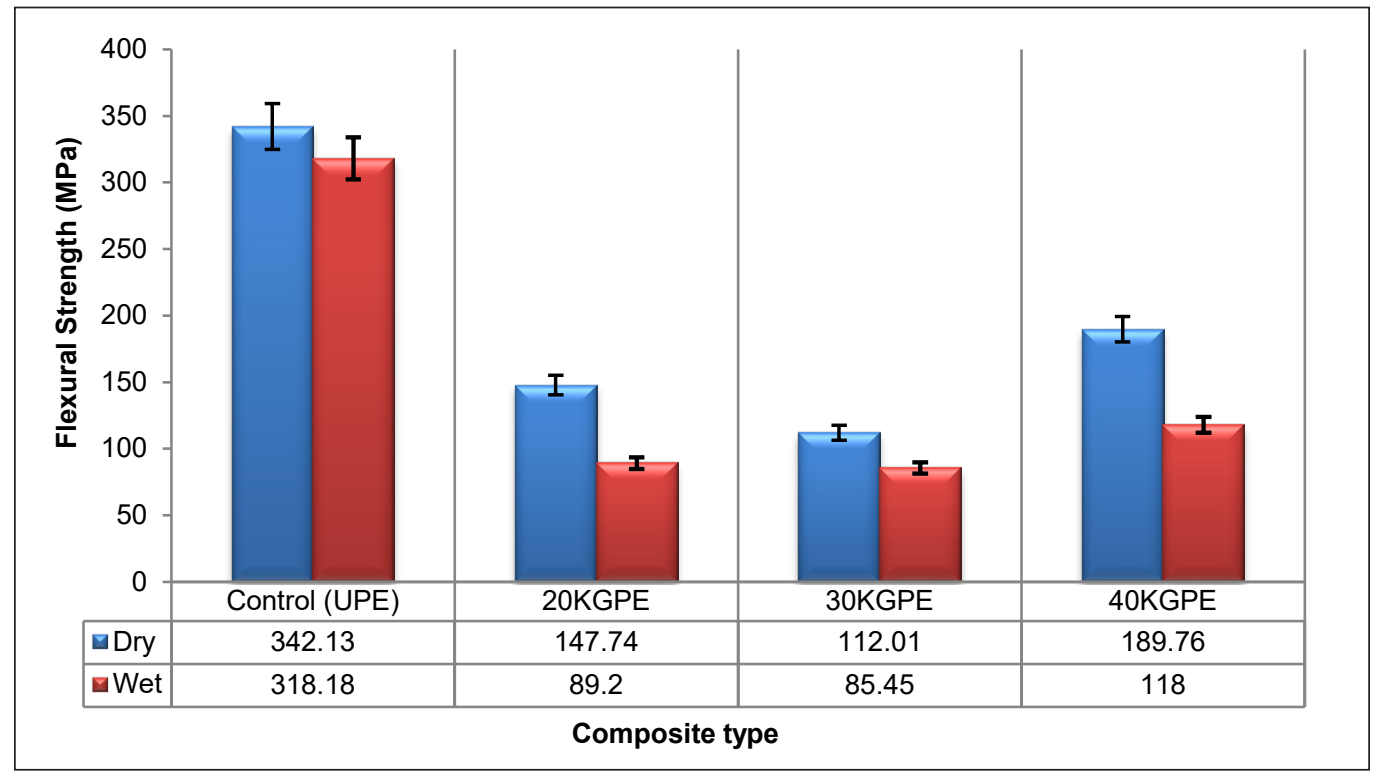

Figure 3. Flexural properties of kenaf/glass fibre hybrid composites reinforced unsaturated polyester, before and after water absorption 
areas between two different fibres showed relatively stable flexural strength. The flexural properties of hybrid composites are affected by water absorption and interface adherence with resin when the same fibre, resin, volume fraction, and fibres arrangement were used. Natural fibres essentially contribute to the strength of natural/synthetic hybrid composites. The higher strength fibres give higher strength composites.

Additionally, the higher aspect ratio (length to width) of kenaf fibre supplies methodical stress transfer in the interface of fibres and matrix. A design of an outer layer of glass fibre surrounding a single kenaf fibre enhanced the mechanical properties and decreased the water absorption compared to the other arrangement profiles (Akil et al., 2014). Conversely, increasing the volume fraction of kenaf fibres gives water absorption, which entails an inoperative stress transfer in the matrix/fibre interface. The flexural strength of 20KGPE composite and 40KGPE composite decreases by $40 \%$ and $38 \%$ after water absorption, respectively, while there is a decrease of only $23.7 \%$ for $30 \mathrm{KGPE}$ composites. Previous work by Yahya et al. (2016) also reported the same finding whereby kenaf fibre arrangement significantly impacted the flexural properties of the hybrid composite after the water absorption test. The flexural strength of mixed kenaf-glass fibres arrangement is profoundly influenced by water absorption, while concentrated kenaf fibre in the hybrid composite core is only slightly affected. In the flexural test, the failure occurred due to bending and shear failures. As a result of the effect of water absorption on flexural properties, flexural strength decreased after water absorption while shear failure resistance had increased.

\section{Scanning Electron Microscopy (SEM)}

Figures 4(a), 4(b), and 4(c) revealed SEM analysis of flexural fracture surface of kenaf/ glass fibre hybrid composites before water absorption and Figures 4(d), 4(e), and 4(f) demonstrated SEM analysis of the flexural surface of kenaf/glass fibre hybrid composites after water absorption test.

From the microscopic images in Figures 4(a) and 4(b), slight debonding and fracture could be noticed in the composites tested before water absorption. In this case, the interfacial relation of fibres to a dry matrix was not very significant, as modes of slight debonding and breakdown of fibre were observed rather than entire fibre pull-out, which is a common thermosetting resins fracture. Therefore, fibre breakage was the primary failure mode for the dry composites. In the meantime, the matrix cracking was observed on the top of Figure 4(c). A close interface between the glass fibres and the UPE matrix produced splits across the extended fibres. Nevertheless, different patterns of surface fractures have been observed in the composites under moisten circumstances. It was evident that the surfaces of the hybrid composites at the fracture area became bumpy and rough. Water absorption might produce matrix delamination and damage to the fibres, where the matrix delamination was very clear, as shown in Figures 4(d) and 4(e). Water absorption 


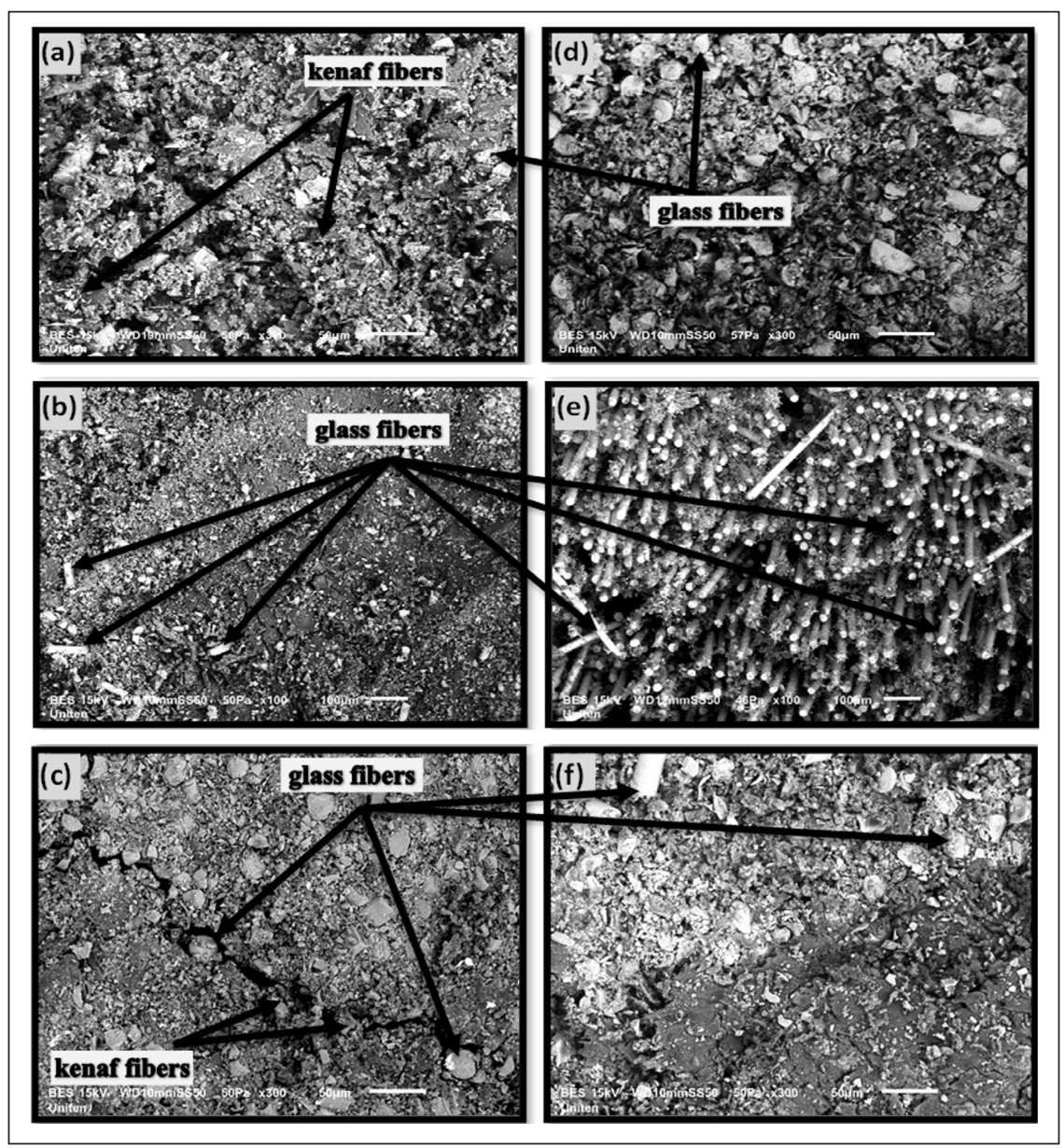

Figure 4. SEM flexural fracture of kenaf/glass fibre hybrid composites ((a), (b), and (c) before water absorption test, (d), (e), and (f) after water absorption test).

debonds the matrix bindings, which decreases the strength of fibre-matrix bonding and enables water to permeate by capillary effect, leading to swelling of the composite. The swelling condition happens in the composite due to water accumulation, which causes stress in the components. An increase of several voids can be observed in the composites after water absorption, as shown in Figures 4(d), 4(e), and 4(f). The increase in the number of voids was due to water absorption by fibres that led to debonding between fibre-fibre and fibres-resin in the composite. These voids work as concentrators of stress, which led to the failure of the composite.

Moreover, the failure of the hybrid composite after water absorption was initiated by the failure of the kenaf fibres due to absorbing more water (hydrophilic fibres). The presence of water molecules in these fibres for a long time made them wet, decreasing the interfacial bindings, thus reducing composites' mechanical and physical characteristics. It 
was noted that kenaf fibres in the fracture surface of composites after water uptake did not appear because water absorbed by kenaf fibres reduced the energy absorption resulting in lower toughness and flexural properties of hybrid composites. In addition, water soaking up also increases the amount of kenaf fibre pulled out owing to diminished bonding force between kenaf, glass fibres and matrix. Initially, the applied force was taken up by kenaf fibres and, after it collapsed, the applied load was transferred to the glass fibre, which finally caused the failure of the hybrid composite. From all figures, it can be seen that there is a low kenaf fibre content at the fracture area. Based on morphology attained, the fracture mechanism appeared to encompass different fibres breaking types, macro fracture of fibres and pull-out fibres from the matrix, similar to the result observed by Hojo et al. (2014). Therefore, the water absorption contributes to decreasing the flexural strength of the hybrid composites. The flexural strength reduction depends on the kenaf fibre arrangements more than its volume fraction.

\section{CONCLUSIONS}

Kenaf fibre was chosen and exploited to manufacture hybrid glass fibre reinforced polymer using the pultrusion technique for insulator applications. Water absorption, whether through moisture or rain, is considered the main threat to the mechanical properties of the polymeric insulator rod. Usually, the insulator rod is protected by rubber, silicon, and paint layers to prevent water from entering the insulator surface except for particular situations, such as erosion or abrasion of the protection layers.

In this study, the flexural characteristics of three different types of kenaf/glass reinforced UPE hybrid composite were tested and analysed before and after water absorption. In addition, SEM observation of fractural cross-section was also performed, and the following conclusion points can be drawn:

- The hybridisation kenaf/glass fibre reinforced UPE was successfully fabricated using the pultrusion method.

- The water absorption of kenaf/glass fibre hybrid composite increased from 8 to 10 times compared with pure glass fibre composite.

- The fibre arrangement profiles and their volume proportion influenced water absorption and flexural properties.

- The kenaf fibres in 20KGPE and 40KGPE composite types increased the water absorption by $10 \%$ and $8 \%$, which caused a decrease in flexural strength of $40 \%$ and $38 \%$, respectively.

- The kenaf fibres arrangement of $30 \mathrm{KGPE}$ (concentrated in the centre of the crosssection) decreased the flexural strength to $112 \mathrm{MPa}$ (lowest value) compared with other composite types. At the same time, the water absorption was the highest 
percentage (10\%). Notwithstanding that, the influence of water absorption on flexural strength was very low $(\approx 2.5 \%)$.

- The SEM morphology observed that the water absorption by kenaf fibre reduced the toughness due to decreased energy absorption and reduced flexural properties.

- The fracture pattern of dry specimens was similar for all composite types but differed in the composites under water-saturated conditions.

\section{ACKNOWLEDGEMENTS}

The authors would like to acknowledge Tenaga Nasional Berhad Malaysia's financial support from a seed fund grant (Project Code: U-TS-RD-18-10), Institute of Power Engineering, Department of Mechanical Engineering, and UNITEN R\&D Sdn. Bhd., Universiti Tenaga Nasional, Malaysia, for the funding to publish these project outcomes.

\section{REFERENCES}

Akil, H. M., Santulli, C., Sarasini, F., Tirillò, J., \& Valente, T. (2014). Environmental effects on the mechanical behaviour of pultruded jute/glass fibre-reinforced polyester hybrid composites. Composites Science and Technology, 94, 62-70. https://doi.org/10.1016/j.compscitech.2014.01.017

Ansari, M. N. M., Bassam, A., Nazim, A. R. M., Nordin, N. A., \& Yahya, Z. (2021). Water absorption of kenaf/glass/epoxy hybrid composites for insulator core. IOP Conference Series: Materials Science and Engineering, 1128(1), Article 012027. https://doi.org/10.1088/1757-899x/1128/1/012027

Aslan, M., Mehmood, S., \& Madsen, B. (2013). Effect of consolidation pressure on volumetric composition and stiffness of unidirectional flax fibre composites. Journal of Materials Science, 48(10), 3812-3824. https://doi.org/10.1007/s10853-013-7182-3

ASTM Standard (2010). ASTM D5229 - Moisture absorption properties and equilibrium conditioning of polymer matrix composite materials. Retrieved April 30, 2020, from https://www.trl.com/astm_d5229_moisture absorption_properties_and_equilibrium_conditioning_of_polymer_matrix_composite_materials/

Azwa, Z. N., \& Yousif, B. F. (2013). Characteristics of kenaf fibre/epoxy composites subjected to thermal degradation. Polymer Degradation and Stability, 98(12), 2752-2759. https://doi.org/10.1016/j. polymdegradstab.2013.10.008

Bansal, A., Schubert, A., Balakrishnan, M. V., \& Kumosa, M. (1995). Finite element analysis of substation composite insulators. Composites Science and Technology, 55(4), 375-389. https://doi.org/10.1016/02663538(95)00120-4

Bansal, A. (1996). Finite element simulation and mechanical characterization of composite insulators. ProQuest Dissertations Publishing.

Bassam, A., Ansari, M. N. M., Atiqah, A., Begum, S., \& Nazim, A. R. M. (2019). Water absorption properties of kenaf/glass reinforced unsaturated polyester composites used in insulator rods. International Journal of Engineering and Advanced Technology, 9(2), 4208-4212. https://doi.org/10.35940/ijeat.b4931.129219 
César dos Santos, J., Ávila de Oliveira, L., Panzera, T. H., Remillat, C. D. L., Farrow, I., Placet, V., \& Scarpa, F. (2020). Ageing of autoclaved epoxy/flax composites: Effects on water absorption, porosity and flexural behaviour. Composites Part B: Engineering, 202, Article 108380. https://doi.org/10.1016/j. compositesb.2020.108380

Dahy, H. (2019). Natural fibre-reinforced polymer composites (NFRP) fabricated from lignocellulosic fibres for future sustainable architectural applications, case studies: Segmented-shell construction, acoustic panels, and furniture. Sensors (Switzerland), 19(3), Article 738. https://doi.org/10.3390/s19030738

Ellyin, F., \& Maser, R. (2004). Environmental effects on the mechanical properties of glass-fiber epoxy composite tubular specimens. Composites Science and Technology, 64(12), 1863-1874. https://doi. org/10.1016/j.compscitech.2004.01.017

Fares, O., AL-Oqla, F. M., \& Hayajneh, M. T. (2019). Dielectric relaxation of mediterranean lignocellulosic fibers for sustainable functional biomaterials. Materials Chemistry and Physics, 229(November 2018), 174-182. https://doi.org/10.1016/j.matchemphys.2019.02.095

Ghosh, D., Bhandari, S., Chaki, T. K., \& Khastgir, D. (2015). Development of a high performance high voltage insulator for power transmission lines from blends of polydimethylsiloxane/ethylene vinyl acetate containing nanosilica. RSC Advances, 5(71), 57608-57618. https://doi.org/10.1039/c5ra08277c

Hamidon, M. H., Sultan, M. T. H., \& Ariffin, A. H. (2018). Investigation of mechanical testing on hybrid composite materials. In M. Jawaid, M. Thariq \& N. Saba (Eds), Failure analysis in biocomposites, fibre-reinforced composites and hybrid composites (pp. 133-156). Woodhead Publishing. https://doi. org/10.1016/b978-0-08-102293-1.00007-3

Hamdan, M. H. M., Siregar, J. P., Cionita, T., Jaafar, J., Efriyohadi, A., Junid, R., \& Kholil, A. (2019). Water absorption behaviour on the mechanical properties of woven hybrid reinforced polyester composites. International Journal of Advanced Manufacturing Technology, 104(1-4), 1075-1086. https://doi. org/10.1007/s00170-019-03976-9

Hamouda, T., Hassanin, A. H., Saba, N., Demirelli, M., Kilic, A., Candan, Z., \& Jawaid, M. (2019). Evaluation of mechanical and physical properties of hybrid composites from food packaging and textiles wastes. Journal of Polymers and the Environment, 27(3), 489-497. https://doi.org/10.1007/s10924-019-01369-3

Hashemi, F., Brancheriau, L., \& Tahir, P. M. (2018). Hybridization and yarns configuration effects on flexural dynamic and static properties of pultruded hybrid kenaf/glass fiber composites. Composites Part A: Applied Science and Manufacturing, 112, 415-422. https://doi.org/10.1016/j.compositesa.2018.05.008

Hashemi, F., Tahir, P. M., Madsen, B., Jawaid, M., Majid, D. L., Brancheriau, L., \& Juliana, A. H. (2016). Volumetric composition and shear strength evaluation of pultruded hybrid kenaf/glass fiber composites. Journal of Composite Materials, 50(17), 2291-2303. https://doi.org/10.1177/0021998315602948

Hojo, T., Xu, Z., Yang, Y., \& Hamada, H. (2014). Tensile properties of bamboo, jute and kenaf mat-reinforced composite. Energy Procedia, 56, 72-79. https://doi.org/10.1016/j.egypro.2014.07.133

Kabir, M. M., Wang, H., Lau, K. T., \& Cardona, F. (2012). Composites: Part B chemical treatments on plantbased natural fibre reinforced polymer composites: An overview. Composites Part B, 43(7), 2883-2892. https://doi.org/10.1016/j.compositesb.2012.04.053 
Khan, Z., Tehami, W., \& Mehmood, Z. (2019). Effect of moisture / liquid absorption on mechanical properties of composites. In 2019 Sixth International Conference on Aerospace Science and Engineering (ICASE) (pp. 1-8). IEEE Publishing. https://doi.org/10.1109/ICASE48783.2019.9059227

Kumosa, L., Benedikt, B., Armentrout, D., \& Kumosa, M. (2004). Moisture absorption properties of unidirectional glass/polymer composites used in composite (non-ceramic) insulators. Composites Part A: Applied Science and Manufacturing, 35(9), 1049-1063. https://doi.org/10.1016/j.compositesa.2004.03.008

Li, C., Xian, G., \& Li, H. (2018). Water absorption and distribution in a pultruded unidirectional carbon/glass hybrid rod under hydraulic pressure and elevated temperatures. Polymers, 10(6), Article 627. https://doi. org/10.3390/polym10060627

Li, H., Xian, Y., Deng, J., Cheng, H., Chen, F., \& Wang, G. (2016). Evaluation of water absorption and its influence on the physical-mechanical properties of bamboo-bundle laminated veneer lumber. BioResources, 11(1), 1359-1368. https://doi.org/10.15376/biores.11.1.1359-1368

Liu, W., Chen, T., Fei, M. E., Qiu, R., Yu, D., Fu, T., \& Qiu, J. (2019). Properties of natural fiber-reinforced biobased thermoset biocomposites: Effects of fiber type and resin composition. Composites Part B: Engineering, 171(March), 87-95. https://doi.org/10.1016/j.compositesb.2019.04.048

Ma, G., Yan, L., Shen, W., Zhu, D., Huang, L., \& Kasal, B. (2018). Effects of water, alkali solution and temperature ageing on water absorption, morphology and mechanical properties of natural FRP composites: Plant-based jute vs. mineral-based basalt. Composites Part B: Engineering, 153(May), 398-412. https:// doi.org/10.1016/j.compositesb.2018.09.015

Mishra, K., Pandey, G., \& Singh, R. P. (2017). Enhancing the mechanical properties of an epoxy resin using polyhedral oligomeric silsesquioxane (POSS) as nano-reinforcement. Polymer Testing, 62, 210-218. https://doi.org/10.1016/j.polymertesting.2017.06.031

Nayak, R. K., Mahato, K. K., \& Ray, B. C. (2016). Water absorption behavior, mechanical and thermal properties of nano $\mathrm{TiO}_{2}$ enhanced glass fiber reinforced polymer composites. Composites Part A: Applied Science and Manufacturing, 90, 736-747. https://doi.org/10.1016/j.compositesa.2016.09.003

Nunna, S., Chandra, P. R., Shrivastava, S., \& Jalan, A. K. (2012). A review on mechanical behavior of natural fiber based hybrid composites. Journal of Reinforced Plastics and Composites, 31(11), 759-769. https:// doi.org/10.1177/0731684412444325

Ouarhim, W., Zari, N., \& Bouhfid, R. (2019). Mechanical performance of natural fibers-based thermosetting composites. In M. Jawaid, M. Thariq \& N. Saba (Eds), Mechanical and physical testing of biocomposites, fibre-reinforced composites and hybrid composites (pp. 43-60). Woodhead Publishing. https://doi. org/10.1016/B978-0-08-102292-4.00003-5

Quino, G., Tagarielli, V. L., \& Petrinic, N. (2020). Effects of water absorption on the mechanical properties of GFRPs. Composites Science and Technology, 199(May), Article 108316. https://doi.org/10.1016/j. compscitech.2020.108316

Rajeshkumar, G. (2020). An experimental study on the interdependence of mercerization, moisture absorption and mechanical properties of sustainable Phoenix sp. fibre-reinforced epoxy composites. Journal of Industrial Textiles, 49(9), 1233-1251. https://doi.org/10.1177/1528083718811085 
Saba, N., Paridah, M. T., Abdan, K., \& Ibrahim, N. A. (2016). Effect of oil palm nano filler on mechanical and morphological properties of kenaf reinforced epoxy composites. Construction and Building Materials, 123, 15-26. https://doi.org/10.1016/j.conbuildmat.2016.06.131

Saba, N., Paridah, M. T., \& Jawaid, M. (2015). Mechanical properties of kenaf fibre reinforced polymer composite: A review. Construction and Building Materials, 76, 87-96. https://doi.org/10.1016/j. conbuildmat.2014.11.043

Sanjay, M. R., Madhu, P., Jawaid, M., Senthamaraikannan, P., Senthil, S., \& Pradeep, S. (2018). Characterization and properties of natural fiber polymer composites: A comprehensive review. Journal of Cleaner Production, 172, 566-581. https://doi.org/10.1016/j.jclepro.2017.10.101

Sapiai, N., Jumahat, A., \& Mahmud, J. (2015). Flexural and tensile properties of kenaf/glass fibres hybrid composites filled with carbon nanotubes. Jurnal Teknologi Full, 11, 87-95.

Sarikaya, E., Çallioğlu, H., \& Demirel, H. (2019). Production of epoxy composites reinforced by different natural fibers and their mechanical properties. Composites Part B: Engineering, 167(15), 461-466. https:// doi.org/10.1016/j.compositesb.2019.03.020

Seman, S. A. H. A., Ahmad, R., \& Akil, H. M. (2019). Meso-scale modelling and failure analysis of kenaf fiber reinforced composites under high strain rate compression loading. Composites Part B: Engineering, 163(May 2018), 403-412. https://doi.org/10.1016/j.compositesb.2019.01.037

Soares, B., \& Preto, R. (2016). Thermo-mechanical modeling of a high pressure turbine blade of an airplane gas turbine engine Mechanical behavior of basalt fibers in a basalt-UP composite Mechanical behavior of basalt fibers composite. Procedia Structural Integrity, 1, 82-89. https://doi.org/10.1016/j.prostr.2016.02.012

Swain, P. T. R., Das, S. N., Patnaik, P. K., \& Purohit, A. (2020). The influence of moisture absorption on the mechanical and thermal properties of chemically treated DPL reinforced hybrid composite. Materials Science Forum, 978, 316-322. https://doi.org/10.4028/www.scientific.net/MSF.978.316

Vickers, L., Rickard, W. D. A., \& Van Riessen, A. (2014). Strategies to control the high temperature shrinkage of fly ash based geopolymers. Thermochimica Acta, 580, 20-27. https://doi.org/10.1016/j.tca.2014.01.020

Yahaya, R., Sapuan, S. M., Jawaid, M., Leman, Z., \& Zainudin, E. S. (2016). Effect of fibre orientations on the mechanical properties of kenaf-aramid hybrid composites for spall-liner application. Defence Technology, 12(1), 52-58. https://doi.org/10.1016/j.dt.2015.08.005

Zhang, K., Liang, W., Wang, F., \& Wang, Z. (2020). Effect of water absorption on the mechanical properties of bamboo/glass-reinforced polybenzoxazine hybrid composite. Polymers and Polymer Composites, 29(1), 3-14. https://doi.org/10.1177/0967391120903664 